\title{
Railway Carriage Model to Study the Influence of Vertical Secondary Stiffness on Ride Comfort of Railway Carbody Running on Curved Tracks
}

\author{
Karim H. Ali Abood (Corresponding author) \& Prof. R. A. Khan \\ Department of Mechanical Eng., Jamia Millia Islamia, New Delhi-110025, India \\ E-mail: karimhali@yahoo.com, rasheed_jmi@hotmail.com
}

Received: December 8, 2010

Accepted: December 27, 2010

doi:10.5539/mas.v5n2p11

\begin{abstract}
A mathematical model of a railway carriage running on curved tracks is constructed by deriving the equations of motion concerning the model in which single-point and two-point wheel-rail contact is considered. The presented railway carriage model comprises of front and rear simple conventional bogies with two leading and trailing wheelets attached to each bogie. The railway carriage is modeled by 31 degrees of freedom which govern vertical displacement, lateral displacement, roll angle and yaw angle dynamic response of wheelset whereas vertical displacement, lateral displacement, roll angle, pitch angle and yaw angle dynamic response of carbody and each of the two bogies. Linear stiffness and damping parameters of longitudinal, lateral and vertical primary and secondary suspensions are provided to the railway carriage model. Combination of linear Kalker's theory and nonlinear Heuristic model is adopted to calculate the creep forces in which introduced at wheel and rail contact patch area. Computer aided-simulation is constructed to solve the governing differential equations of the mathematical model using Runge-Kutta fourth order method. Principle of limit cycle and phase plane approach is applied to realize the stability and evaluate the concerning critical hunting velocity at which railway carriage starts to hunt. The numerical simulation model is used to study the influence of vertical secondary suspension spring stiffness on the ride passenger comfort of railway carbody running with speeds under and at critical hunting velocity. High magnitudes of vertical secondary spring stiffness suspension introduce undesirable roll and yaw dynamic response in which affect ride passenger comfort at critical hunting velocity. Low critical hunting velocity with railway carriage running on curved tracks can be represented.
\end{abstract}

Keywords: Railway carriage, Railway carbody, Curved tracks, Ride comfort, Yaw response, Roll response, Critical hunting velocity

\section{Introduction}

Study the dynamic behavior of railway carriage due to some external inputs such as rail irregularities, sudden disturbances, rail maneuvers, breaking or accelerating and other imperfections can be achieved by Dynamic response analysis. Problems arise due to these undesirable inputs when railway carriage begin to move in different directions as vertical, pitch, roll, lateral and yaw directions. These movements cause vibrations and damage in railway components with uncomfortable ride passenger. Lateral displacements occur due to imperfections and irregularities in the track which cause different undesirable motions like roll, yaw, and pitch. Lateral forces arise in the wheel-rail contact patch plane due to interactions between the wheel and the rail which force wheelsets to move laterally and may climb the rail. These introduced forces called creep forces in which depend upon different creep coefficients. The magnitudes of creep coefficients depend upon the wheel-rail geometry, normal load, and material properties. Many investigations used different magnitudes of creep coefficients and a combination of linear Kalker's theory (Kalker, J. J., 1979) and nonlinear Heuristic is used in the present study. The study of railway carriage dynamic behavior should take into account the responses of railway carriage to these displacements and movements and more degrees of freedom should be considered to verify the accuracy of the system model. Different railway carriage models with different degrees of freedom are investigated and presented by many papers concerning railway carriage dynamic response. Dynamic stability of railway vehicle wheelsets and bogies having profiled wheels was presented by Wickens (Wicknes, A.H., 1969) in which two degrees of freedom model was suggested govern lateral and yaw angle of each wheelset. Nonlinear mathematical model of dynamic simulation has been established with 7 degrees of freedom by Jawahar et al. (Jawahar, P. M., and Gupta, K. N., 1990) which govern lateral and yaw movements of wheelsets and lateral, yaw and roll movements for both conventional and unconventional bogies. Xu et al. (Xu, Y.L., Xia, H., Yan, Q.S., 
2002)( Xu, Y.L., Ding, Q.S., 2006) studied the dynamic analysis of coupled train-bridge systems under fluctuating wind and stated a railway carriage model that each 4-axle vehicle in a train is modeled by 27 degrees of freedom dynamic system. A vehicle model by Wang (Wang, T.L., 1992) was developed to represent a 23 degrees of freedom conventional freight car, consisting of a carbody, two bolsters and two truck assemblies where the carbody was assigned five degrees of freedom govern vertical lateral, yaw, pitch, and roll while each bolster was assigned three degrees of freedom vertical, lateral and roll motion. Nath et al. (Nath, Y., Jayadev, K., 2005) studied the influence of yaw stiffness on the nonlinear dynamics of railway wheelset used two degrees of freedom model which govern the lateral and yaw motions. Nonlinear differential equations modeled by 8 and 10 degrees of freedom of railway carriage moving on curved tracks are presented by Lee et al. (Sen-Yung Lee, and Yung-Chang Cheng, 2005)( Sen-Yung Lee, and Yung-Chang Cheng, 2006). Train vehicle model considered by Kumaran et al. (Kumaran, G. Devadas Menon, Krishnan Nair, K., 2003) conforming to Indian railways consists of a vehicle body, two bogies with four wheelsets in which the system is modeled by 17 degrees of freedom. Mohan (Mohan, A., 2003) developed a method to eliminate hunting behavior in rail vehicles by increasing the critical hunting velocity and using railway carriage model comprising carbody, two bogies with four wheelsets, in which the railway model assigned four degrees of freedom which govern lateral and yaw motions of each wheelset and lateral motion of left and right tracks whereas the full vehicle 25 degrees of freedom which govern lateral, yaw and roll motions. Study the effects of railway track imperfections on track dynamic behavior, and the effect of unsupported sleepers on the normal load of wheel-rail were investigated by Zhang et al. (Shuguang Zhang, Xinbiao Xiao, Zefeng Wen, and Xuesong Jin, 2007) in which the system is modeled by 35 degrees of freedom that consider the lateral and vertical displacement, roll, pitch and yaw angle for the carbody, front and rear bogie frames and the four wheelsets. An ideal truck model with full frame decoupling represented by Dukkipati et al. (Dukkipati, Rao V., and Narayana Swamy, S., 2001)( Dukkipati, Rao V., and Narayana Swamy, S., 2001) which is modeled by 8 degrees of freedom. An investigation of dynamic interaction of long suspension bridges with running trains is presented by Xia et al. (Xia, H., Y.L., Xu, Y.L., Chan, T.H.T, 2000) in which a 27 degrees of freedom model is used. A new finite element model for three-dimensional analysis of high-speed train-bridge interactions is proposed by Song et al. (Myung-Kwan Song, Hyuk-Chun Noh, Chang-Koon Choi, 2003) in which the equations of motion of the vehicle-bridge were derived using Lagrange's equation where the carbody is considered with four degrees of freedom which govern bouncing, swaying, pitching, and yawing whereas bouncing, sliding, swaying, pitching, rolling and yawing motions are considered for the bogie. Li et al. (Ping Li, Roger Goodall, Paul Weston, Chung Seng Ling, Colin Goodman, Clive Roberts, 2007) investigated the problem of railway vehicle suspension estimation in which lateral and yaw modes are important and wheelsets and bogie have two degrees of freedom which govern lateral and yaw motions. A nonlinear model of a single wheelset moving with constant speed on a purely straight track is presented by Pater (De Pater, A. D., 1980), Thus the equations of motion were written down either as six equations containing the normal forces, or as four equations which do not contain the normal forces. Yugat et al. (Jesus Otero Yugat, Jordi Martinze Mirulles, Maria De Los Santos, 2009) presented an analytical model of wheel-rail contact force due to the passage of a railway vehicle on a curved track used equations of motion govern vertical and roll motion of right and left wheel while vertical motion of right and left rail. A nonlinear wagon-track model with 23 degrees of freedom is presented by Sun et al. (Sun, Y. Q., Simson, S., 2008) used to study rail corrugation formation due to the wheel stick-slip process. Rajib et al. (Rajib Ul Alam Uzzal, Waiz Ahmed, Subhash Rakheja, 2008) presented equations of motion govern vertical motion of front and rear wheelset, bounce and pitch motion of bogie and bounce motion of carbody to study the dynamic analysis of railway vehicle-track interactions. Railway vehicle dynamics during motion along a curved track is examined by Zboinski (Krzysztof Zboinski, 1998)( Krzysztof Zboinski, 1999) in which the dynamic behavior of the system is studied using two different methods, the quasi-statical and dynamical approach. In additional the research concerned the influence of vehicle suspension parameters as well as conditions of motion (speed, super-elevation, curve radius, transition curve existence) on limit cycle occurrence. The present study considers a railway carriage consists of carbody, two bogies and four conventional wheelsets modeled by 31-degrees of freedom which govern bounce, pitch, roll, lateral, and yaw motions of the system. The procedure done in this study is to derive the second order governing differential equations of motion of the full railway carriage and transformed these equations into a set of first order differential equations using especial technique to facilitate solving them with numerical methods. Computer-aided simulation is used to solve these equations with Runge Kutta fourth-order method and represent the dynamic behavior of the system running with speeds under and at critical hunting velocity. Principle of limit cycle approach (Dukkipati, Rao V., and Narayana Swamy, S., 2001) is used to specify the critical hunting velocity of the system in which subjected to different magnitudes of vertical secondary spring stiffness suspension. The dynamic responses of railway carriage carbody subjected to specific parameters of primary suspension characteristics and to different 
magnitudes of vertical secondary spring stiffness suspension are investigated using the constructed numerical simulation model. A comparison to study the sensitivity of railway carriage carbody to dynamic responses is also presented.

\section{Mathematical Railway Carriage Model}

The equations of motion of the considered railway carriage model are derived using Newton's second law. Inertial, suspension and creep forces are introduced and used to construct the whole differential equations of motion of the railway carriage model. Many researches derived the equations of motion using Newton's second law but with different degrees of freedom as mentioned in the above introduction such as in (Jawahar, P. M., and Gupta, K. N., 1990)(Sen-Yung Lee, and Yung-Chang Cheng, 2006)( Mohan, A., 2003). The railway carriage is a combination of components and wheelsets joining together by a set of different primary and secondary suspension elements, in which the full railway carriage configuration model system consists of carbody, two conventional bogies, and four wheelsets as shown in Figure 1. A railway carriage model of 31 degrees of freedom is constructed in this research to study the dynamic responses at critical hunting velocity of railway carriage components moving on curved tracks. The differential equations of motion govern lateral displacement $Y_{w}, Y_{b}, Y_{c}$ vertical displacement $Z_{w}, Z_{b}, Z_{c}$ roll angle $\phi_{w}, \phi_{b}, \phi_{c}$ and yaw angle $\psi_{w}, \psi_{b}, \psi_{c}$ of wheelset, bogie and carbody respectively while pitch angle $\theta_{b}, \theta_{c}$ of bogie and carbody. Railway carriage model is equipped with eight longitudinal, lateral and vertical primary suspensions of spring stiffness $K_{p x}$, $K_{p y}, K_{p z}$ respectively and viscous damping constant $C_{p x}, C_{p y}, C_{p z}$ respectively. Also the system is provided with eight longitudinal, lateral and vertical secondary suspensions of spring stiffness $K_{s x}, K_{s y}, K_{s z}$ respectively and viscous damping constant $C_{s x}, C_{s y}, C_{s z}$ respectively. Symbols and notations are illustrated in the nomenclature in Table 1. Dynamic behavior of railway carriage is caused by wheel-rail interactions in which creep forces are introduced at wheel-rail contact patch area. Non-conservative forces and elastic deformations at the contact patch introduce a phenomenon of creep and combination of linear Kalker's theory (Kalker, J. J., 1979) and nonlinear Heuristic is considered to calculate the introduced creep forces. Vibrations are transmitted through connected suspensions to other railway carriage components and the dynamical behavior of the system is governed by the equations of motion of each component of railway carriage.

\subsection{Wheelsets Differential Equations of Motion}

The railway carriage model is equipped with four conventional wheelsets in which consists of two wheels attached together by a solid axle. Wheelsets are used to steer and support the carriage. Wheelsets equations of motion are derived using Newton's laws with suspension, creep and normal forces in which some of these forces are calculated by Sen et al. (Myung-Kwan Song, Hyuk-Chun Noh, Chang-Koon Choi, 2003). The Vertical, Lateral, Roll and Yaw equations of motion of single wheelset are

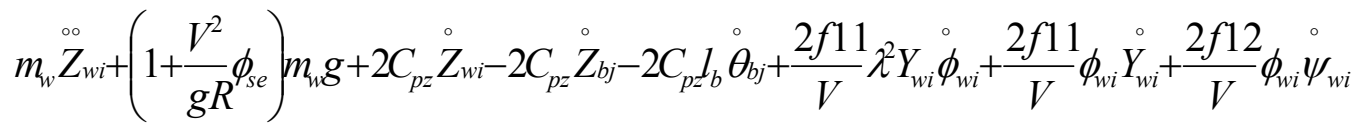

$$
\begin{aligned}
& +\frac{2 f 1 r_{0}}{V} \phi_{w i} \dot{\circ}_{w i}+2 K_{p z} Z_{w i}-2 K_{p z} Z_{b i}-2 K_{p z} l_{b} \theta_{b j}-\frac{2 f 12}{r_{0}} \lambda^{2}=0 \\
& J_{w x} \stackrel{\circ}{\phi}_{w i}+\left(\frac{2 f_{11} a r_{o} \lambda}{V}+\frac{2 f_{11} r_{o}^{2}}{V}\right) \dot{\phi}_{w i}+\frac{2 f_{11}\left(r_{o}+a \lambda\right)}{V} \dot{\circ}_{w i} \\
& -\left(\frac{J_{w y} V}{r_{o}}-\frac{2 f_{12} r_{o}}{V}-\frac{2 f_{12} a \lambda}{V}\right) \stackrel{\circ}{\psi}_{w i}+2 C_{p z} l_{s} \stackrel{\circ}{Z}_{w i}-2 C_{p z} l_{s} \stackrel{\circ}{Z}_{b j}-2 C_{p z} l_{s} l_{b} \stackrel{\circ}{\theta}_{b j} \\
& -\left(2 \lambda^{2} f_{12}+a \lambda W\right) \phi_{w i}-\left(\frac{2 f_{12} \lambda^{2}}{r_{o}} \lambda^{2} W\right) Y_{w i}-\left(2 f_{11}\left(r_{o}+a \lambda\right)+\frac{2 f_{22} \lambda^{2}}{r_{o}}\right) \psi_{w i} \\
& +2 K_{p z} l_{s} Z_{w i}-2 K_{p z} l_{s} Z_{b j}-2 K_{p z} l_{s} l_{b} \theta_{b j}=0
\end{aligned}
$$




$$
\begin{aligned}
& m_{w} \stackrel{\circ}{w i}_{w}-\left(\frac{V^{2}}{g R}-\phi_{s e}\right) m_{w} g+\left(\frac{2 f 11}{V}-2 C_{p y}\right) \stackrel{\circ}{Y_{w i}}+2 C_{p y} \stackrel{\circ}{Y}_{b j}+\frac{2 f 12}{V} \dot{\psi}_{w i}+\frac{2 r_{0} f 11^{\circ}}{V} \phi_{w i}-2 K_{p y} Y_{w i}+2 K_{p y} Y_{b j} \\
& -2 f 11 \psi_{w i}+W \phi_{w i}=0
\end{aligned}
$$$$
\begin{aligned}
& J_{w z} \stackrel{\circ}{w i}_{w i}+\left[\left(\frac{2 a^{2} f_{33}}{V}+\frac{2 f_{22}}{V}\right)+2 C_{p x} L_{x}^{2}\right] \dot{\psi}_{w i}-\frac{2 f_{12}}{V} \stackrel{\circ}{Y}_{w i}-\left(-\frac{J_{w y} V}{r_{o}}+\frac{2 r_{o} f_{12}}{V}\right) \dot{\phi}_{w i} \\
& -2 C_{p x} L_{x}{ }^{2} \stackrel{\circ}{\psi}_{b j}+\left[2 K_{p x} L_{x}^{2}-\left(-2 f_{12}+a \lambda W\right)\right] \psi_{w i}-\frac{2 a \lambda f_{33}}{r_{o}} Y_{w i}-2 K_{p x} L_{x}{ }^{2} \psi_{b j}=0
\end{aligned}
$$

\subsection{Bogies Differential Equations of Motion}

Railway carriage model consists of two bogies in which each bogie has two conventional unconnected front and rear wheelsets and two vertical secondary suspension elements are used to connect bogies with carbody in additional to the set of primary suspension elements connected each bogie with the wheelsets. The bogies differential equations of motion govern vertical, pitch, roll, lateral, and yaw degrees of freedom are

$$
\begin{aligned}
& m_{b} \stackrel{\circ}{Z}_{b j}+\left(1+\frac{V^{2}}{g R} \phi_{s e}\right) m_{b} g+\left(2 C_{s z}+4 C_{p z}\right) \stackrel{\circ}{Z}_{b j}-2 C_{s z} l_{c} \stackrel{\circ}{\theta}_{c}-2 C_{s z} \stackrel{\circ}{Z}_{c}-2 C_{p z} \stackrel{\circ}{Z}_{w i}-2 C_{p z} \stackrel{\circ}{Z}_{w i} \\
& +\left(2 K_{s z}+4 K_{p z}\right) Z_{b i}-2 K_{s z} l_{c} \theta_{c}-2 K_{s z} Z_{c}-2 K_{p z} Z_{w i}-2 K_{p z} Z_{w i}=0 \\
& J_{b y} \stackrel{\circ}{\theta}_{b j}+4 C_{p z} l_{b}^{2} \stackrel{\circ}{\theta}_{b j}-2 C_{p z} l_{b} \stackrel{\circ}{Z}_{w i}+2 C_{p z} l_{b} \stackrel{\circ}{Z}_{w i}+4 K_{p z} l_{b}^{2} \theta_{b j}-2 K_{p z} l_{b} Z_{w i}+2 K_{p z} l_{b} Z_{w i}=0 \\
& \left.J_{b x} \stackrel{\circ}{\phi}_{b j}+\left(4 C_{p z}+2 C_{s z}\right)\right)_{s}^{2} \stackrel{\circ}{\phi}_{b j}-2 C_{s z} l_{s}^{2} \stackrel{\circ}{\phi}_{c}-2 C_{p z} l_{s}^{2} \stackrel{\circ}{\phi}_{w i}-2 C_{p z} l_{s}^{2} \stackrel{\circ}{\phi}_{w i}-2 C_{s y} L_{c s} l_{c} \dot{\circ}_{c} \\
& +4 C_{p y} L_{c s} \stackrel{\circ}{Y}_{b j}-2 C_{p y} L_{c s} \stackrel{\circ}{Y}_{w i}-2 C_{p y} L_{c s} \stackrel{\circ}{Y}_{w i}+\left(4 K_{p z}+2 K_{s z}\right) l_{s}^{2} \phi_{b j}-2 K_{s z} l_{s}^{2} \phi_{c}-2 K_{p z} l_{s}^{2} \phi_{w i} \\
& -2 K_{p z} l_{s}^{2} \phi_{w i}-2 K_{s y} h_{c s} l_{c} \psi_{c}+4 K_{p y} L_{c s} Y_{b j}-2 K_{p y} L_{c s} Y_{w i}-2 K_{p y} L_{c s} Y_{w i}=0 \\
& m_{b} \stackrel{\circ}{Y}_{b j}-\left(\frac{V^{2}}{g R}-\phi_{s e}\right) m_{b} g+\left(2 C_{s y}+4 C_{p y}\right) \stackrel{\circ}{Y}_{b j}-2 C_{s y} \stackrel{\circ}{Y}_{c}-2 C_{p y} \stackrel{\circ}{Y}_{w i}-2 C_{p y} \stackrel{\circ}{Y}_{w i} \\
& +\left(2 K_{s y}+4 K_{p y}\right) Y_{b j}-2 K_{s y} Y_{c}-2 K_{p y} Y_{w i}-2 K_{p y} Y_{w i}=0 \\
& J_{b z} \stackrel{\circ}{\psi}_{b j}-\left(-4 L_{x}{ }^{2} C_{p x}-4 L_{b}^{2} C_{p y}\right) \dot{\circ}_{b j}-2 L_{x}{ }^{2} C_{p x} \stackrel{\circ}{\psi}_{w i}-2 L_{x}{ }^{2} C_{p x} \stackrel{\circ}{\psi}_{w i}-2 L_{b} C_{p y} \stackrel{\circ}{Y}_{w 1}+2 L_{b} C_{p y} \stackrel{\circ}{Y}_{w i} \\
& -\left(-4 L_{x}^{2} K_{p x}-4 L_{b}^{2} K_{p y}\right) \psi_{b j}-2 L_{x}^{2} K_{p x} \psi_{w i}-2 L_{x}^{2} K_{p x} \psi_{w i}-2 L_{b} K_{p y} Y_{w i}+2 b K_{p y} Y_{w i}=0
\end{aligned}
$$

\subsection{Carbody Differential Equations of Motion}

Carbody is the heaviest component in railway carriage makes crush between wheel and track and elastic deformation is introduced at contact patch area to produce creep forces and moments. Carbody differential equations of motion govern bounce, pitch, roll, lateral, and yaw degrees of freedom are derived applying Newton's law. The derived equations of motion of carbody with mass $m_{c}$ and moment of inertia about longitudinal axis $J_{c x}$, about lateral axis $J_{c y}$, and about bounce axis $J_{c z}$ are

$$
\begin{aligned}
& m_{c} \stackrel{\circ}{Z}_{c}+\left(1+\frac{V^{2}}{g R} \phi_{s e}\right) m_{c} g+4 C_{s z} \stackrel{\circ}{Z}_{c}-2 C_{s z} \stackrel{\circ}{Z}_{b j}-2 C_{s z} \stackrel{\circ}{Z}_{b j}+4 K_{s z} Z_{c}-2 K_{s z} Z_{b j} \\
& -2 K_{s z} Z_{b j}=0
\end{aligned}
$$




$$
\begin{aligned}
& J_{c y} \stackrel{\circ}{\theta}_{c}+4 C_{s z} l_{c}^{2} \stackrel{\circ}{\theta}_{c}-2 C_{s z} l_{c} \stackrel{\circ}{Z}_{b j}+2 C_{s z} l_{c} \stackrel{\circ}{Z}_{b j}+4 K_{s z} l_{c}^{2} \theta_{c}-2 K_{s z} l_{c} Z_{b j} \\
& +2 K_{s z} l_{c} Z_{b j}=0 \\
& J_{c x} \stackrel{\circ}{\phi}_{c}+4 C_{s z} l_{s}^{2} \stackrel{\circ}{\phi}_{c}-2 C_{s z} l_{s}^{2} \stackrel{\circ}{\phi}_{b j}-2 C_{s z} l_{s}^{2} \stackrel{\circ}{\phi}_{b j}+4 C_{s y} L_{c s} \stackrel{\circ}{Y}_{c}-2 C_{s y} L_{c s} \stackrel{\circ}{Y}_{b j}-2 C_{s y} L_{c s} \stackrel{\circ}{Y}_{b j} \\
& +4 K_{s z} l_{s}^{2} \phi_{c}-2 K_{s z} l_{s}^{2} \phi_{b j}-2 K_{s z} l_{s}^{2} \phi_{b j}+4 K_{s y} L_{c s} Y_{c}-2 K_{s y} L_{c s} Y_{b j}-2 K_{s y} L_{c s} Y_{b j}=0 \\
& m_{c} \stackrel{\circ}{Y}_{c}-\left(\frac{V^{2}}{g R}-\phi_{s e}\right) m_{c} g+4 C_{s y} \stackrel{\circ}{Y}_{c}-2 C_{s y} \stackrel{\circ}{Y}_{b j}-2 C_{s y} \stackrel{\circ}{Y}_{b j}+4 L_{c s} C_{s y} \dot{\phi}_{c}+4 K_{s y} Y_{c} \\
& -2 K_{s y} Y_{b j}-2 K_{s y} Y_{b j}+\left(m_{c} g+4 L_{c s} K_{s y}\right) \phi_{c}=0 \\
& J_{c z}^{\circ} \stackrel{\circ}{c}_{c}+2\left(2 l_{c}^{2} C_{s y}+C_{s x}\right) \dot{\circ}_{c}-C_{s x} \stackrel{\circ}{\psi}_{b j}-C_{s x} \dot{\circ}_{b j}-2 l_{c} C_{s y} \stackrel{\circ}{Y}_{b j}+2 l_{c} C_{s y} \stackrel{\circ}{Y}_{b j} \\
& +2\left(2 l_{c}^{2} K_{s y}+K_{s x}\right) \psi_{c}-K_{s x} \psi_{b j}-K_{s x} \psi_{b j}-2 l_{c} K_{s y} Y_{b j}+2 l_{c} K_{s y} Y_{b j}=0
\end{aligned}
$$

\section{Numerical Simulation}

Railway carriage running on curved tracks is modeled by the second order differential equations of motion (1-14). A simple and important technique used to transform the governing equations of motion into first order differential equations in suitable form known as state space equations. This technique is used to facilitate solving the equations with numerical integration methods. The transformed equations of motion are simulated with computer-aided simulation to be solved by Runge-Kutta fourth order numerical method. Table 2 represents the data used in numerical simulation from resources (Dukkipati, Rao V., and Narayana Swamy, S., 2001)( De Pater, A. D., 1980) also initial conditions are assumed for the dynamic motions of the system. Simulation is executed to represent the dynamic responses of railway carriage carbody subjected to different magnitudes of vertical secondary spring stiffness suspension under and at critical hunting velocity. Procedure is achieved by increasing the speeds to reach the critical velocity and principles of phase plane approach are utilized to represent the critical hunting velocity of the system.

\section{Results}

Simulation model is constructed to study and analyze railway ride comfort of car body under and at critical hunting velocity due to change in spring stiffness of vertical secondary suspension. Ride passenger comfort can be investigated through lateral, yaw, roll, pitch and vertical dynamic motions and displacements of railway carbody running on curved tracks with radius of curved track R and super elevation angle of curved track is $\phi_{s e}$. Most of the computed responses of the present railway carriage model are compared with many previous studies to ensure that the railway carriage model is valid to use to study the dynamic responses of the system. Also the magnitudes in which obtained by the computer simulation are acceptable values compared with most of the magnitudes introduced by other previous studies such as in most of the researches in the reference. Figures 2-6 show the dynamic response of the railway carbody under critical hunting velocity with different magnitudes of vertical secondary spring stiffness and it can be figured out that the dynamic response returns to a steady state equilibrium point at different time of dynamic responses. Vertical and pitch dynamic response returns to stable equilibrium point within time less than lateral, yaw and roll dynamic response at all the different magnitudes of vertical secondary spring stiffness also these dynamic responses have less amplitudes than vertical and pitch displacements. Also limited high magnitude of vertical secondary spring stiffness (Ksz) gives small dynamic displacements and improve hunting phenomenon of the carbody but roll, vertical and pitch dynamic responses are more sensitive to change in vertical secondary spring stiffness than lateral and yaw dynamic responses. The magnitudes of railway carbody dynamic displacements obtained from the simulation model show that better ride comfort in railway carbody at speed under critical hunting velocity with appropriate high spring stiffness of vertical secondary suspension. Lateral, yaw and roll dynamic responses are more sensitive to critical hunting velocity than vertical and pitch dynamic response as shown in Figures 7-11 in which represent the dynamic behavior of railway carriage at critical hunting velocity. Figure 7 shows the lateral dynamic response of railway carriage at critical hunting velocity with different magnitudes of vertical spring stiffness secondary suspension 
and it can be observed that lateral response is more sensitive to critical hunting velocity. In additional small change in magnitudes of lateral displacement arises due to high vertical spring stiffness. High magnitudes of vertical spring stiffness secondary suspension have distinct influence at yaw and roll dynamic response at critical hunting velocity and will increase the hunting instability of railway carbody as shown in Figures 8-9. The railway carbody response to vertical and pitch displacements is shown in Figures 10-11 in which no effect of critical hunting velocity to these displacements and change in spring stiffness still the same to railway carbody with speed under critical hunting velocity.

\section{Conclusion}

The railway carriage simulated model constructed in the present study is able to explain the dynamic response of the system with different magnitudes of vertical secondary spring stiffness suspension. As mentioned in the results section that lateral, yaw and roll dynamic response of the railway carriage carbody is more sensitive to the hunting velocity than the vertical and pitch dynamic response of the carbody. That means more attention should be considered to improve ride comfort by making improvement with the parameters related to lateral, yaw and roll dynamic response such as suspension parameters. Figures indicate that roll, vertical and pitch dynamic response of the carbody are more sensitive to change in vertical secondary spring stiffness suspension than lateral and yaw dynamic response. That means the roll dynamic response of the carbody is the most dynamic response can be improved to satisfy the ride comfort of railway carriage carbody due to change in magnitudes of vertical secondary spring stiffness suspension. Also itis concluded that high magnitudes of spring stiffness vertical suspension applied to railway carriage gives good results in ride passenger comfort at speeds under critical hunting velocity but with speeds at critical hunting velocity it has distinct influence at yaw and roll dynamic displacement so the present simulation model can be used to choice the appropriate magnitude of the spring stiffness of vertical secondary suspension. The dynamic response of the railway carriage running on curved tracks stated low critical hunting velocity.

\section{References}

De Pater, A. D. (1980). A Nonlinear Model of a Single Wheelset Moving With Constant Speed on a Purely Straight Track, Int. J. of Non-Linear Mechanics, 15, pp. 315-324.

Dukkipati, Rao V., and Narayana Swamy, S. (2001). Lateral Stability and Steady State Curving Performance of Unconventional Rail Truck, Mechansim and Machine Theory, 36, pp. 577-587.

Dukkipati, Rao V., and Narayana Swamy, S. (2001). Non-Linear Steady-State Curving Analysis of Some Unconventional Rail Trucks, Mechansim and Machine Theory, 36, pp. 507-521.

Jawahar, P. M., and Gupta, K. N. (1990). Mathematical Modeling for Lateral Dynamic Simulation of a Railway Vehicle with Conventional and Unconventional Wheelsets, Math. And Computer Modeling J., 14, pp. 989-994.

Jesus Otero Yugat, Jordi Martinze Mirulles, Maria De Los Santos. (2009). Analytical model of wheel-rail contact force due to the passage of a railway vehicle on a curved track. Rev. Fac. Ing. Univ. Antioquia No. 50 pp. 135-144.

Kalker, J. J. (1979). Survey of Wheel-Rail Rolling Contact Theory, Vehicle System Dynamics J., 5, pp. 317-358.

Krzysztof Zboinski. (1998). Dynamical Investigation of Railway Vehicles on a Curved Track, J. Mech. And Solids, 17, pp. 1001-1020.

Krzysztof Zboinski. (1999). Importance of Imaginary Forces and Kinematic Type Non-Linearities for Description of Railway Vehicle Dynamics, Procceeding of the IMECHE Part F, Journal of Rail and Rapid Transit, 213(4), pp. 199-210.

Kumaran, G. Devadas Menon, Krishnan Nair, K. (2003). Dynamic Studies of Rail Track Sleepers in a Track Structure System, Journal of Sound and Vibration, Vol. 268, pp. 485-501.

Mohan, A. (2003). Nonlinear Investigation of The Use of Controllable Primary Suspensions to Improve Hunting in Railway Vehicles, Msc. Thesis, Virginia Polytechnic Institute and State University, Virginia.

Myung-Kwan Song, Hyuk-Chun Noh, Chang-Koon Choi. (2003). A new Three-Dimensional Finite Element Analysis Model of High-Speed Train Interactions, 25, pp. 1611-1626.

Nath, Y., Jayadev, K. (2005). Influence of Yaw Stiffness on The Nonlinear Dynamics of Railway Wheelset, Communications in nonlinear Science and Numerical Simulation, Vol. 10, pp. 179-190.

Ping Li, Roger Goodall, Paul Weston, Chung Seng Ling, Colin Goodman, Clive Roberts. (2007). Estimation of Railway Vehicle Suspension Parameters for condition monitoring, Journal of Control Engineering Practice, 
Vol. 15, pp. 43-55.

Rajib Ul Alam Uzzal, Waiz Ahmed, Subhash Rakheja. (2008). Dynamic Analysis of Railway Vehicle-Track Interactions Due to Wheel Flat With a Pitch-Plane Vehicle Model, Journal of Mechanical Engineering, Vol. ME 39, pp.86-94.

Sen-Yung Lee, and Yung-Chang Cheng. (2005). Hunting Stability Analysis of Higher-Speed Railway Vehicle Trucks on Tangent Tracks, Journal of Sound and Vibration, 282, pp. 881-898.

Sen-Yung Lee, and Yung-Chang Cheng. (2006). Influences of The Vertical and The Roll Motions of Frames on The Hunting Stability of Trucks Moving on Curved Tracks, Journal of Sound and Vibration, 294, pp. 441-453.

Shuguang Zhang, Xinbiao Xiao, Zefeng Wen, and Xuesong Jin. (2007). Effect of Unsupported Sleepers on Wheel/Rail Normal Load, Journal of Soil Dynamics and Earthquake Engineering, doi:10.1016/j.soildyn.08.006.

Sun, Y. Q., Simson, S. (2008). Wagon-Track Modeling and Parameteric Study on Rail Corrugation Initiation Due to Wheel Stick-Slip Process on Curved Track, Simulation Modeling Practice and Theory, 17, pp. 22-34.

Wang, T.L. (1992). Impact in a Railway Truss Bridge, Computers and structures journal, pp. 1045-1054.

Wicknes, A.H. (1969). The Dynamic Stability of Railway Vehicle Wheelsets and_Bogies Having Profiled Wheels, International Journal of Solids and Structures_Vol.1, pp. 319-341.

Xia, H., Y.L., Xu, Y.L., Chan, T.H.T. (2000). Dynamic Interaction of Long Suspension Bridges with Running Trains, Journal of Sound and Vibration, 237(2), pp. 263-280.

Xu, Y.L., Ding, Q.S. (2006). Interaction of Railway Vehicles With Track in Cress-Wind, Journal of Fluids and Structures, Vol. 22, pp. 295-314.

Xu, Y.L., Xia, H., Yan, Q.S. (2002). Dynamic Analysis of Coupled Train-Bridge Systems Under Fluctuating Wind, Advances in Steel Structure, pp. 889-896.

Table 1. Nomenclature

\begin{tabular}{|l|l|l|l|}
\hline $\mathrm{m}_{\mathrm{w}}$ & Mass of wheelset & $f_{11}$ & Lateral creep forces coefficient \\
\hline $\mathrm{m}_{\mathrm{b}}$ & Mass of bogie & $f_{12}$ & Lateral-spin creep forces coefficient \\
\hline $\mathrm{m}_{\mathrm{c}}$ & Mass of carbody & $f_{22}$ & Spin creep forces coefficient \\
\hline $\mathrm{W}$ & Weight of wheelset & $f_{3}$ & Longitudinal creep forces coefficient \\
\hline $\mathrm{r} 0$ & Nominal wheel rolling radius & $\mathrm{V}$ & Forward speed of railway carriage \\
\hline $\mathrm{Y}_{\mathrm{wi}}$ & $\begin{array}{l}\text { Lateral displacement of wheelset }(\mathrm{i}=1,2,3, \\
4)\end{array}$ & $\mathrm{Y}_{\mathrm{bj}}$ & Lateral displacement of bogie $\mathrm{j}=1,2)$ \\
\hline$\ddot{\mathrm{O}}_{\mathrm{wi}}$ & $\begin{array}{l}\text { Roll angle displacement of wheelset }(\mathrm{i}=1, \\
2,3,4)\end{array}$ & $\ddot{\mathrm{O}}_{\mathrm{bj}}$ & Roll angle displacement of bogie $(\mathrm{j}=1,2)$ \\
\hline$\emptyset_{\mathrm{wi}}$ & $\begin{array}{l}\text { Yaw angle displacement of wheelset }(\mathrm{i}=1, \\
2,3,4)\end{array}$ & $\emptyset_{\mathrm{bj}}$ & Yaw angle displacement of bogie $(\mathrm{j}=1,2)$ \\
\hline $\mathrm{Z}_{\mathrm{c}}$ & $\begin{array}{l}\text { Bounce or vertical displacement of } \\
\text { carbody }\end{array}$ & $\mathrm{Y}_{\mathrm{c}}$ & Lateral displacement of carbody \\
\hline$\ddot{\mathrm{O}}_{\mathrm{c}}$ & Roll angle displacement of carbody & $\grave{\mathrm{E}}_{\mathrm{c}}$ & Pitch angle displacement of carbody \\
\hline $\mathrm{E}_{\mathrm{bj}}$ & Pitch angle displacement of bogie $(\mathrm{j}=1,2)$ & $\emptyset_{\mathrm{c}}$ & Yaw angle displacement of carbody \\
\hline $\mathrm{a}$ & Half of track gauge & $\lambda$ & Wheel profile conicity \\
\hline
\end{tabular}


Table 2.

\begin{tabular}{|c|c|c|c|}
\hline Notation & Parameter & Unit & Value \\
\hline$f_{11}$ & Lateral creep coefficient & $N$ & $9.43 \times 10^{6}$ \\
\hline$f_{12}$ & Lateral/spin creep coefficient & $N . m$ & $1.20 \times 10^{3}$ \\
\hline$f_{22}$ & Spin creep coefficient & $N . m^{2}$ & $1.00 \times 10^{3}$ \\
\hline$f_{33}$ & Forward creep coefficient & $N$ & $10.23 \times 10^{6}$ \\
\hline$m_{w}$ & Mass of wheelset & $K g$ & 1751 \\
\hline$m_{b}$ & Mass of bogie & $K g$ & $3.086 \times 10^{3}$ \\
\hline$m_{c}$ & Mass of carbody & $K g$ & $4.820 \times 10^{4}$ \\
\hline$J_{w x}$ & Roll mass moment of inertia of Wheelset & $K g \cdot m^{2}$ & 761 \\
\hline$J_{w y}$ & Pitch mass moment of inertia of Wheelset & $K g \cdot m^{2}$ & 130 \\
\hline$J_{w z}$ & Yaw mass moment of inertia of Wheelset & $K g . m^{2}$ & 761 \\
\hline$J_{b x}$ & Roll mass moment of inertia of Bogie & $K g . m^{2}$ & $2.312 \times 10^{3}$ \\
\hline$J_{b y}$ & Pitch mass moment of inertia of Bogie & $K g . m^{2}$ & $4.730 \times 10^{3}$ \\
\hline$J_{b z}$ & Yaw mass moment of inertia of Bogie & $K g . m^{2}$ & $4.730 \times 10^{3}$ \\
\hline$J_{c x}$ & Roll mass moment of inertia of Carbody & $K g . m^{2}$ & $8.617 \times 10^{5}$ \\
\hline$J_{c y}$ & Pitch mass moment of inertia of Carbody & $K g \cdot m^{2}$ & $2.999 \times 10^{6}$ \\
\hline$J_{c z}$ & Yaw mass moment of inertia of Carbody & $K g \cdot m^{2}$ & $2.999 \times 10^{6}$ \\
\hline$r_{0}$ & Centered rolling radius of wheel & $m$ & 0.3556 \\
\hline$a$ & Half of track gage & $m$ & 0.716 \\
\hline$d_{p}$ & Half distances between primary longitudinal suspensions & $m$ & 0.61 \\
\hline$\mu$ & Coefficient of friction between wheel and rail & & 0.15 \\
\hline$\lambda$ & Wheel conicity & rad & 0.125 \\
\hline$K_{p x}$ & Longitudinal primary suspension spring stiffness & $N / m$ & $2.85 \times 10^{6}$ \\
\hline$K_{p y}$ & Lateral primary suspension spring stiffness & $N / m$ & $5.85 \times 10^{5}$ \\
\hline$K_{p z}$ & Vertical primary suspension spring stiffness & $N / m$ & $9.32 \times 10^{5}$ \\
\hline$C_{p x}$ & Longitudinal primary damping coefficient & $N . s / m$ & 83760 \\
\hline$C_{p y}$ & Lateral primary damping coefficient & $N . s / m$ & 9048.2 \\
\hline$C_{p z}$ & Vertical primary damping coefficient & $N . s / m$ & $3 \times 10^{4}$ \\
\hline$K_{s y}$ & Lateral secondary suspension spring stiffness & $N / m$ & $3.5 \times 10^{5}$ \\
\hline$K_{s z}$ & Vertical secondary suspension spring stiffness & $N / m$ & Variable \\
\hline$C_{s y}$ & Lateral secondary damping coefficient & $N . s / m$ & $1.75 \times 10^{4}$ \\
\hline$C_{s z}$ & Vertical secondary damping coefficient & $N . s / m$ & $2.75 \times 10^{4}$ \\
\hline$K_{\text {rail }}$ & Lateral rail stiffness & $N / m$ & $14.6 \times 10^{7}$ \\
\hline$C_{\text {rail }}$ & Lateral rail damping coefficient & $N . s / m$ & $14.6 \times 10^{4}$ \\
\hline
\end{tabular}




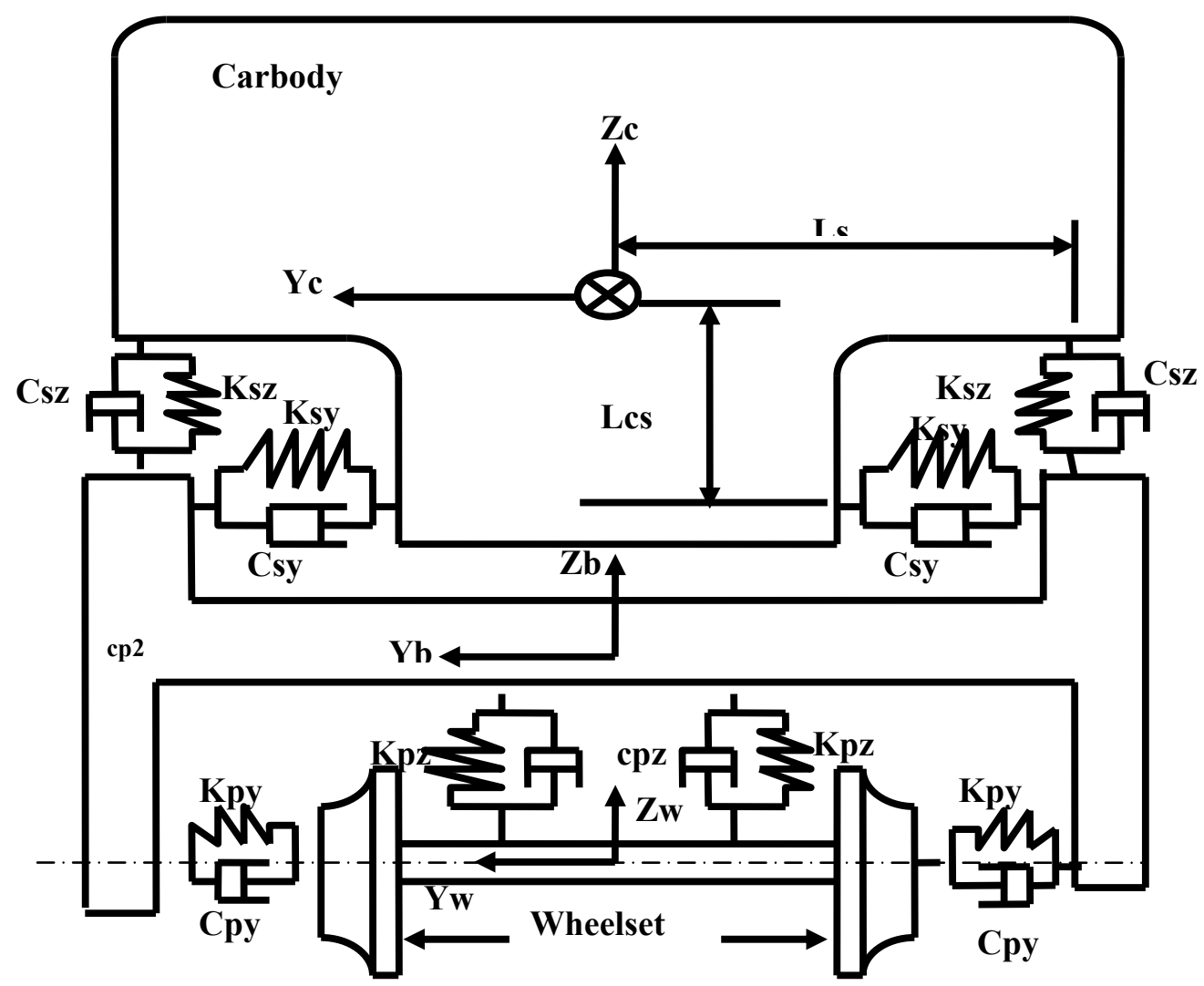

Figure 1. Front view of railway carriage components equipped with sets of primary and secondary suspension elements

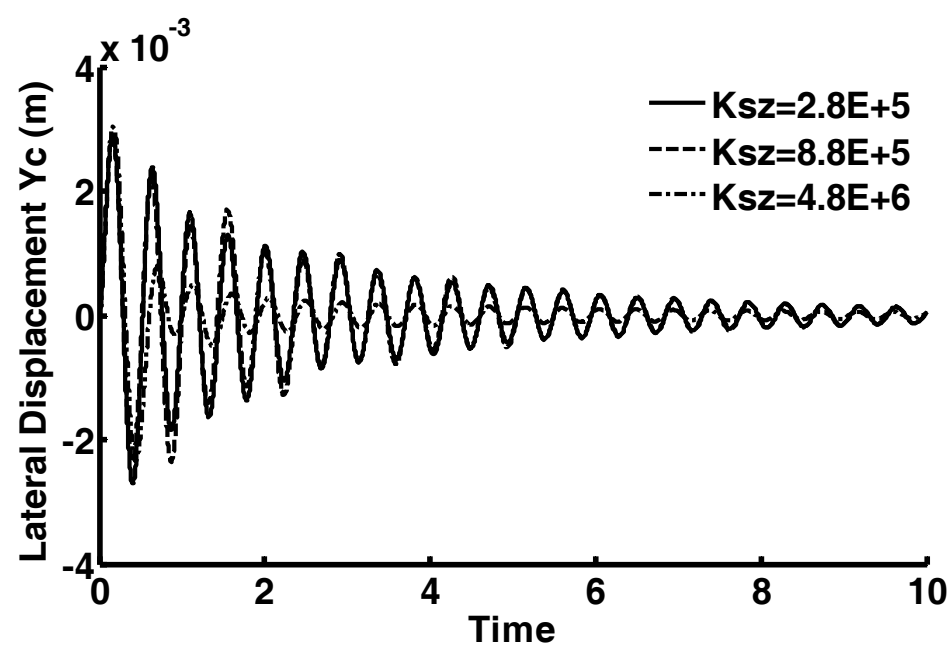

Figure 2. lateral dynamic displacement of carbody in which a component of railway carriage moving on tangent tracks under critical hunting velocity $(76 \mathrm{Km} / \mathrm{h})$ 


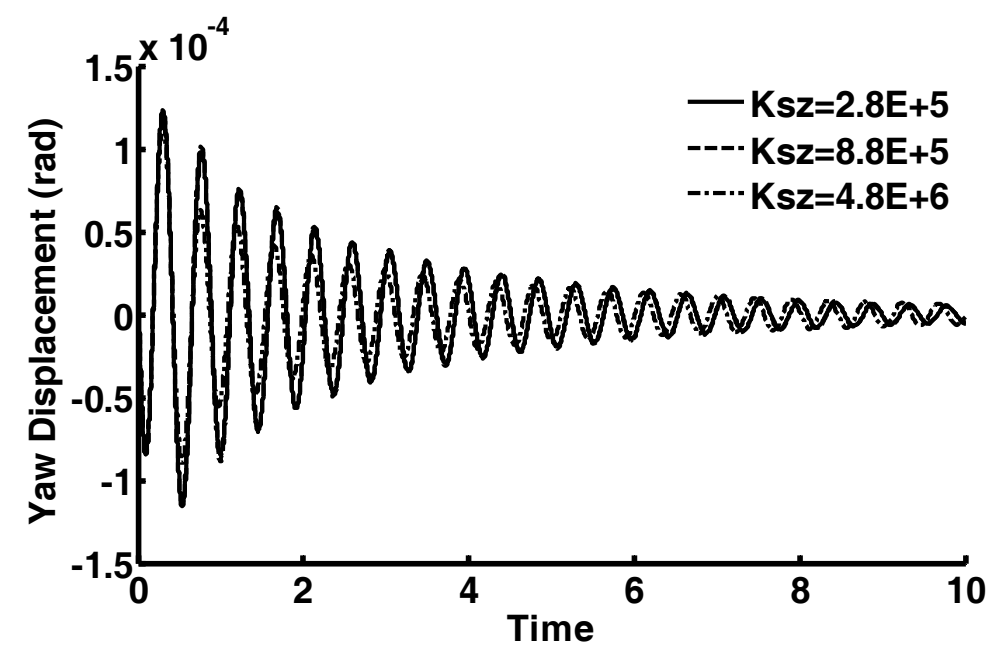

Figure 3. Yaw dynamic displacement of carbody in which a component of railway carriage moving on tangent tracks under critical hunting velocity $(76 \mathrm{Km} / \mathrm{h}$ )

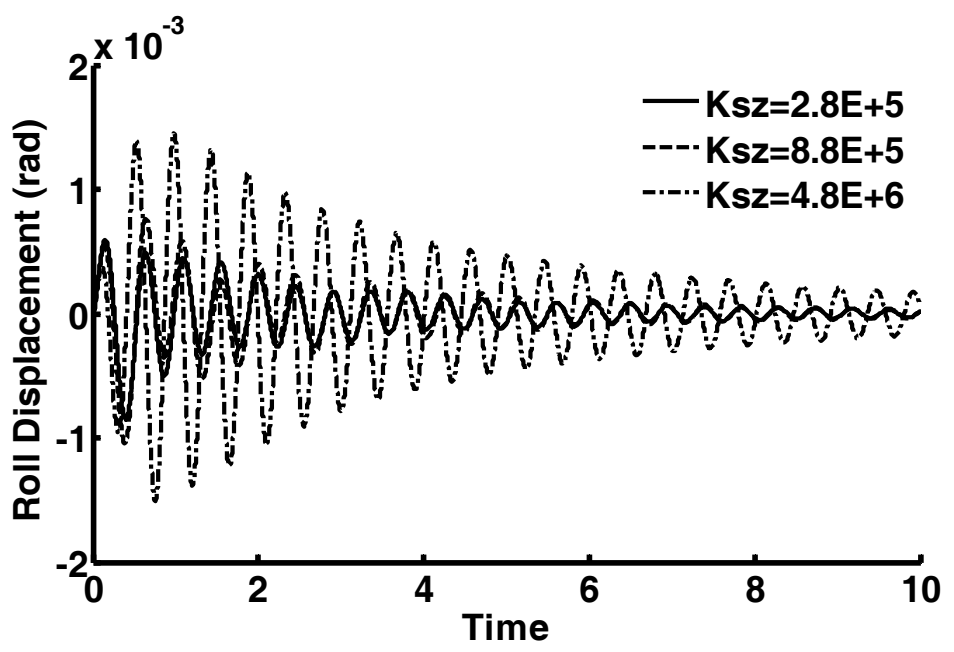

Figure 4. Roll dynamic displacement of carbody in which a component of railway carriage moving on tangent tracks under critical hunting velocity $(76 \mathrm{Km} / \mathrm{h}$ )

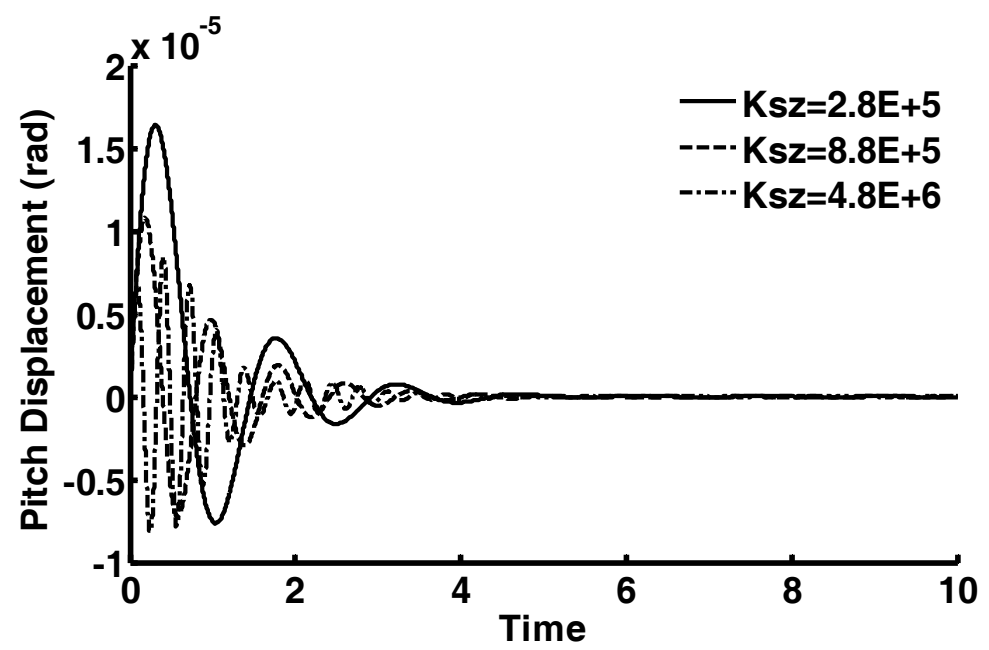

Figure 5. Pitch dynamic displacement of carbody in which a component of railway carriage moving on tangent tracks under critical hunting velocity $(76 \mathrm{Km} / \mathrm{h})$ 


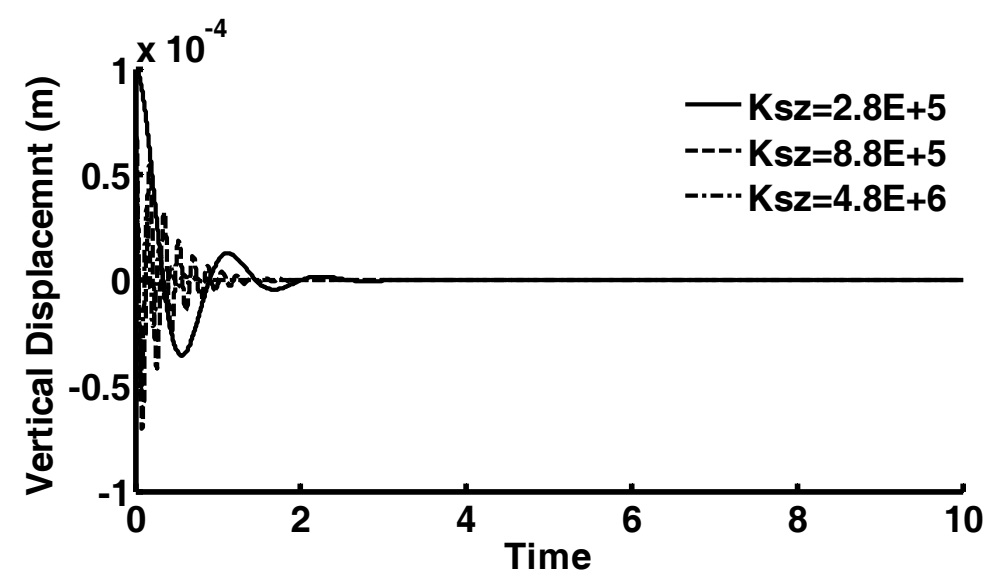

Figure 6. Vertical dynamic displacement of carbody in which a component of railway carriage moving on tangent tracks under critical hunting velocity $(76 \mathrm{Km} / \mathrm{h})$

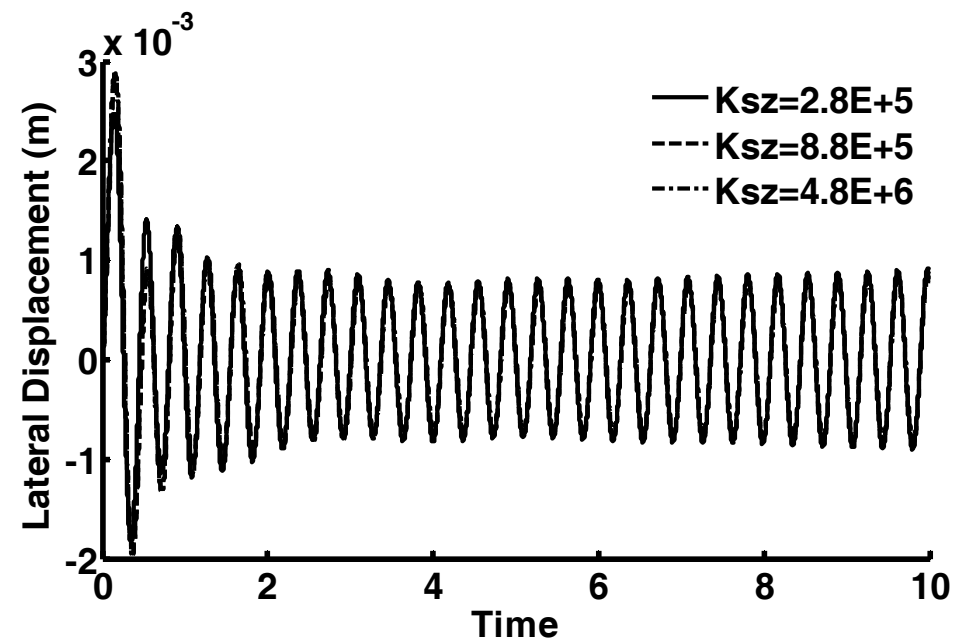

Figure 7. lateral dynamic displacement of carbody in which a component of railway carriage moving on tangent tracks at critical hunting velocity $(114 \mathrm{Km} / \mathrm{h})$

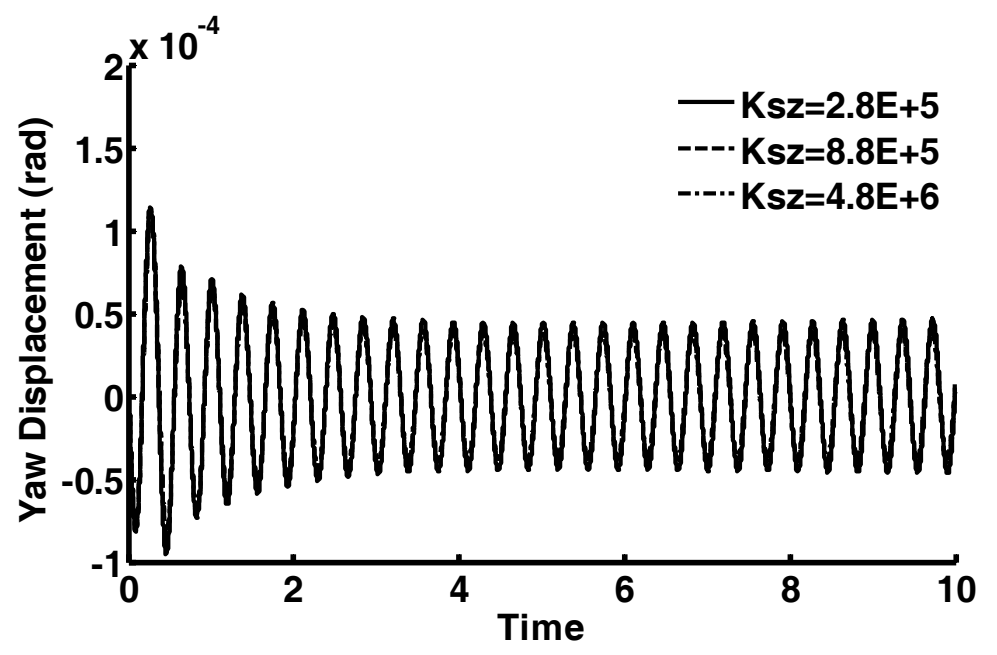

Figure 8.Yaw dynamic displacement of carbody in which a component of railway carriage moving on tangent tracks at critical hunting velocity $(114 \mathrm{Km} / \mathrm{h})$ 


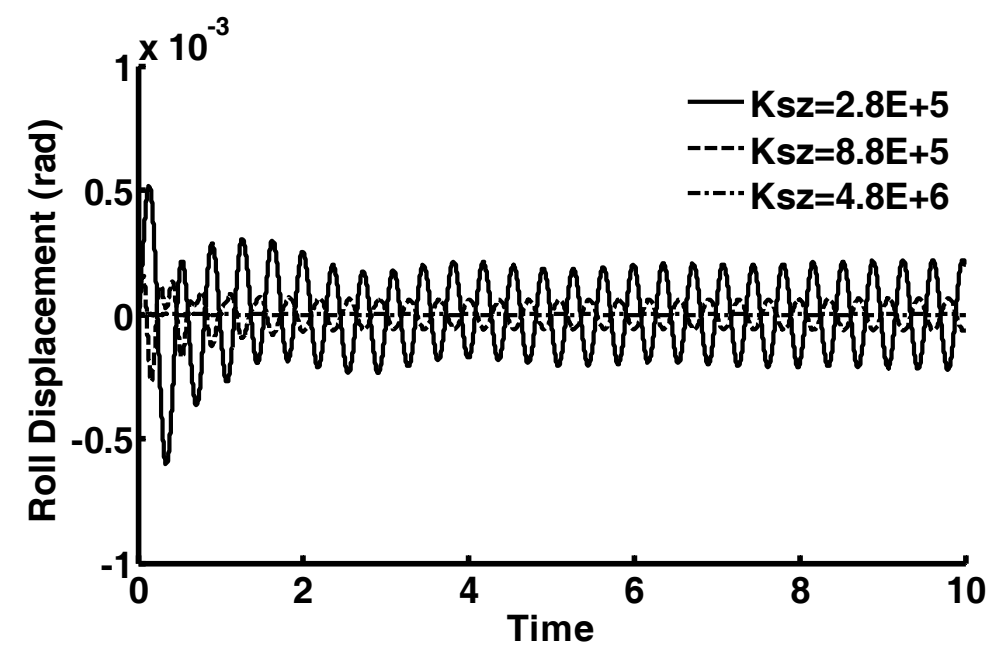

Figure 9. Roll dynamic displacement of carbody in which a component of railway carriage moving on tangent tracks at critical hunting velocity $(114 \mathrm{Km} / \mathrm{h})$

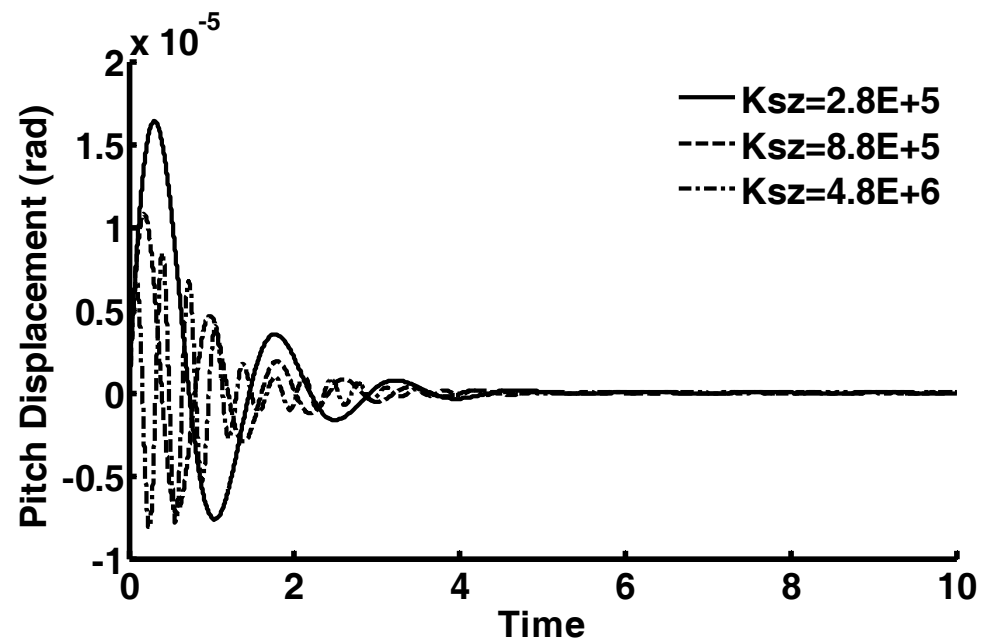

Figure 10. Pitch dynamic displacement of carbody in which a component of railway carriage moving on tangent tracks at critical hunting velocity $(114 \mathrm{Km} / \mathrm{h})$

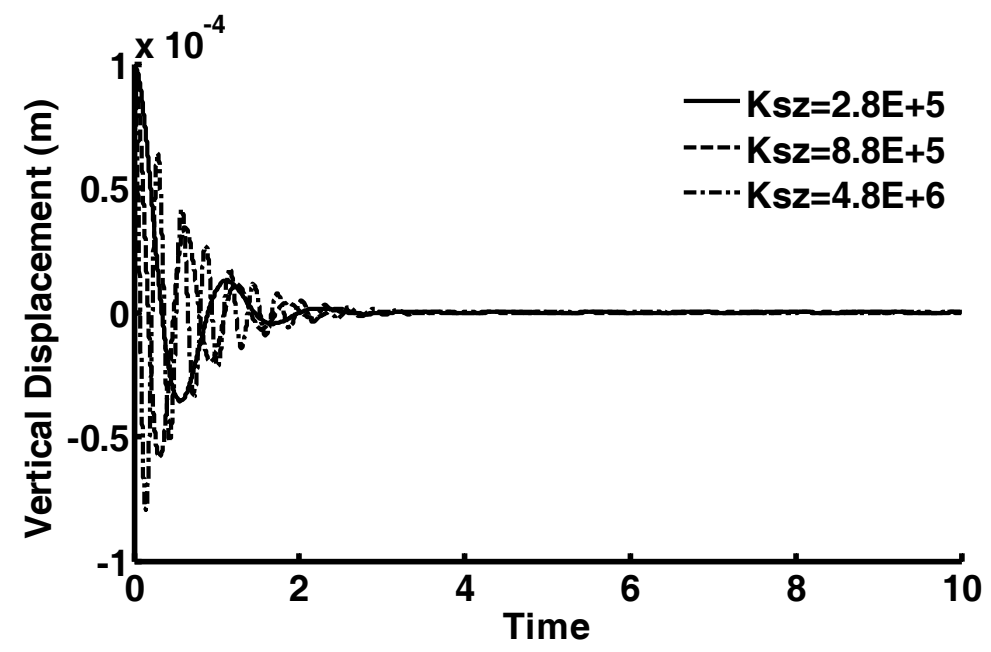

Figure 11. Vertical dynamic displacement of carbody in which a component of railway carriage moving on tangent tracks at critical hunting velocity $(114 \mathrm{Km} / \mathrm{h})$ 


\section{Appendix A}

\section{Transformation Technique}

The second order ordinary differential equations of motion of the railway vehicle should be transformed into first order differential equations in suitable form known as state space equations in order to facilitate solving the equations with numerical integration methods. The procedure steps can be presented as:

Lateral displacement of Wheelset $\mathrm{w}_{1} X_{1}=Y_{w 1} \Rightarrow \stackrel{\circ}{X}_{1}=\stackrel{\circ}{Y}_{w 1}=X_{2} \Rightarrow \stackrel{\circ}{X}_{2}=\stackrel{\circ}{X}_{1}=\stackrel{\circ}{Y}_{w 1}$

Lateral displacement of Wheelset $\mathrm{w}_{2} X_{3}=Y_{w 2} \Rightarrow \stackrel{\circ}{X}_{3}=\stackrel{\circ}{Y}_{w 2}=X_{4} \Rightarrow \stackrel{\circ}{X}_{4}=\stackrel{\circ}{X}_{3}=\stackrel{\circ}{Y}_{w 2}$

Lateral displacement of Wheelset $\mathrm{w}_{3} X_{5}=Y_{w 3} \Rightarrow \stackrel{\circ}{X}_{5}=\stackrel{\circ}{Y}_{w 3}=X_{6} \Rightarrow \stackrel{\circ}{X}_{6}=\stackrel{\circ}{X}_{5}=\stackrel{\circ}{Y}_{w 3}$

Lateral displacement of Wheelset $\mathrm{w}_{4} X_{7}=Y_{w 4} \Rightarrow \stackrel{\circ}{X}_{7}=\stackrel{\circ}{Y}_{w 4}=X_{8} \Rightarrow \stackrel{\circ}{X}_{8}=\stackrel{\circ}{X}_{7}=\stackrel{\circ}{Y}_{w 4}$

Vertical displacement of Wheelset $\mathrm{w}_{1} X_{9}=Z_{w 1} \Rightarrow \stackrel{\circ}{X}_{9}=\stackrel{\circ}{Z}_{w 1}=X_{10} \Rightarrow \stackrel{\circ}{X}_{10}=\stackrel{\circ}{X}_{9}=\stackrel{\circ}{Z}_{w 1}$

Vertical displacement of Wheelset $w_{2} X_{11}=Z_{w 2} \Rightarrow \stackrel{\circ}{X}_{11}=\stackrel{\circ}{Z}_{w 2}=X_{12} \Rightarrow \stackrel{\circ}{X}_{12}=\stackrel{\circ}{X}_{11}=\stackrel{\circ}{Z}_{w 2}$

Vertical displacement of Wheelset $\mathrm{w}_{3} X_{13}=Z_{w 3} \Rightarrow \stackrel{\circ}{X}_{13}=\stackrel{\circ}{Z}_{w 3}=X_{14} \Rightarrow \stackrel{\circ}{X}_{14}=\stackrel{\circ}{X}_{13}=\stackrel{\circ}{Z}_{w 3}$

Vertical displacement of Wheelset $\mathrm{w}_{4} X_{15}=Z_{w 4} \Rightarrow \stackrel{\circ}{X}_{15}=\stackrel{\circ}{Z}_{w 4}=X_{16} \Rightarrow \stackrel{\circ}{X}_{16}=\stackrel{\circ}{X}_{15}=\stackrel{\circ}{Z}_{w 4}$

Yaw displacement of Wheelset $\mathrm{w}_{1} X_{17}=\psi_{w 1} \Rightarrow \stackrel{\circ}{X}_{17}=\stackrel{\circ}{\psi}_{w 1}=X_{18} \Rightarrow \stackrel{\circ}{X}_{18}=\stackrel{\circ}{X}_{17}=\stackrel{\circ}{\psi}$

Yaw displacement of Wheelset $\mathrm{w}_{2} X_{19}=\psi_{w 2} \Rightarrow \stackrel{\circ}{X}_{19}=\stackrel{\circ}{\psi}_{w 2}=X_{20} \Rightarrow \stackrel{\circ}{X}_{20}=\stackrel{\circ}{X}_{19}=\stackrel{\circ}{\psi}_{w 2}$

Yaw displacement of Wheelset $w_{3} X_{21}=\psi_{w 3} \Rightarrow \stackrel{\circ}{X}_{21}=\stackrel{\circ}{\psi}_{w 3}=X_{22} \Rightarrow \stackrel{\circ}{X}_{22}=\stackrel{\circ}{X}_{21}=\stackrel{\circ}{\psi}_{w 3}$

Yaw displacement of Wheelset $\mathrm{w}_{4} X_{23}=\psi_{w 4} \Rightarrow \stackrel{\circ}{X}_{23}=\stackrel{\circ}{\psi}_{w 4}=X_{24} \Rightarrow \stackrel{\circ}{X}_{24}=\stackrel{\circ}{X}_{23}=\stackrel{\circ}{\psi_{w 4}}$

Roll displacement of Wheelset $\mathrm{w}_{1} X_{25}=\phi_{w 1} \Rightarrow \stackrel{\circ}{X}_{25}=\stackrel{\circ}{\phi}_{w 1}=X_{26} \Rightarrow \stackrel{\circ}{X}_{26}=\stackrel{\circ}{X}_{25}=\stackrel{\circ}{\phi}_{w 1}$

Roll displacement of Wheelset $\mathrm{w}_{2} X_{27}=\phi_{w 2} \Rightarrow \stackrel{\circ}{X}_{27}=\stackrel{\circ}{\phi}_{w 2}=X_{28} \Rightarrow \stackrel{\circ}{X}_{28}=\stackrel{\circ}{X}_{27}=\stackrel{\circ}{\phi_{w 2}}$

Roll displacement of Wheelset $\mathrm{w}_{3} X_{29}=\phi_{w 3} \Rightarrow \stackrel{\circ}{X}_{29}=\stackrel{\circ}{\phi}_{w 3}=X_{30} \Rightarrow \stackrel{\circ}{X}_{30}=\stackrel{\circ}{X}_{29}=\stackrel{\circ}{\phi}_{w 3}$

Roll displacement of Wheelset $\mathrm{w}_{4} X_{31}=\phi_{w 4} \Rightarrow \stackrel{\circ}{X}_{31}=\stackrel{\circ}{\phi}_{w 4}=X_{32} \Rightarrow \stackrel{\circ}{X}_{32}=\stackrel{\circ}{X}_{31}=\stackrel{\circ}{\phi_{w 4}}$

Lateral displacement of Front bogie $b_{1} \quad X_{33}=Y_{b 1} \Rightarrow \stackrel{\circ}{X}_{33}=\stackrel{\circ}{Y}_{b 1}=X_{34} \Rightarrow \stackrel{\circ}{X}_{34}=\stackrel{\circ}{X}_{33}=\stackrel{\circ}{Y}_{b 1}$

Lateral displacement of Rear bogie $b_{2} X_{35}=Y_{b 2} \Rightarrow \stackrel{\circ}{X}_{35}=\stackrel{\circ}{Y}_{b 2}=X_{36} \Rightarrow \stackrel{\circ}{X}_{36}=\stackrel{\circ}{X}_{35}=\stackrel{\circ}{Y}_{b 2}$

Vertical displacement of Front bogie $b_{1} \quad X_{37}=Z_{b 1} \Rightarrow \stackrel{\circ}{X}_{37}=\stackrel{\circ}{Z}_{b 1}=X_{38} \Rightarrow \stackrel{\circ}{X}_{38}=\stackrel{\circ}{X}_{37}=\stackrel{\circ}{Z}_{b 1}$

Vertical displacement of Rear bogie $b_{2} X_{39}=Z_{b 2} \Rightarrow \stackrel{\circ}{X}_{39}=\stackrel{\circ}{Z}_{b 2}=X_{40} \Rightarrow \stackrel{\circ}{X}_{40}=\stackrel{\circ}{X}_{39}=\stackrel{\circ}{Z}_{b 2}$

Yaw displacement of Front bogie $b_{1} \quad X_{41}=\psi_{b 1} \Rightarrow \stackrel{\circ}{X}_{41}=\stackrel{\circ}{\psi}_{b 1}=X_{42} \Rightarrow \stackrel{\circ}{X}_{42}=\stackrel{\circ}{X}_{41}=\stackrel{\circ}{\psi}_{b 1}$

Yaw displacement of Rear bogie $b_{2} \quad X_{43}=\psi_{b 2} \Rightarrow \stackrel{\circ}{X}_{43}=\stackrel{\circ}{\psi}_{b 2}=X_{44} \Rightarrow \stackrel{\circ}{X}_{44}=\stackrel{\circ}{X}_{43}=\stackrel{\circ}{\psi}_{b 2}$

Roll displacement of Front bogie $b_{1} X_{45}=\phi_{b 1} \Rightarrow \stackrel{\circ}{X}_{45}=\stackrel{\circ}{\phi}_{b 1}=X_{46} \Rightarrow \stackrel{\circ}{X}_{46}=\stackrel{\circ}{X}_{45}=\stackrel{\circ}{\phi}_{b 1}$

Roll displacement of Rear bogie $b_{2} X_{47}=\phi_{b 2} \Rightarrow \stackrel{\circ}{X}_{47}=\stackrel{\circ}{\phi}_{b 2}=X_{48} \Rightarrow \stackrel{\circ}{X}_{48}=\stackrel{\circ}{X}_{47}=\stackrel{\circ}{\phi}_{b 2}$ 
Pitch displacement of Front bogie $b_{1} X_{49}=\theta_{b 1} \Rightarrow \stackrel{\circ}{X}_{49}=\stackrel{\circ}{\theta}_{b 1}=X_{50} \Rightarrow \stackrel{\circ}{X}_{50}=\stackrel{\circ}{X}_{49}=\stackrel{\circ}{\theta}_{b 1}$

Pitch displacement of Rear bogie $b_{2} \quad X_{51}=\theta_{b 2} \Rightarrow \stackrel{\circ}{X}_{51}=\stackrel{\circ}{\theta}_{b 2}=X_{52} \Rightarrow \stackrel{\circ}{X}_{52}=\stackrel{\circ}{X}_{51}=\stackrel{\circ}{\theta}_{b 2}$

Lateral displacement of Carbody c $X_{53}=Y_{c} \Rightarrow \stackrel{\circ}{X}_{53}=\stackrel{\circ}{Y}_{c}=X_{54} \Rightarrow \stackrel{\circ}{X}_{54}=\stackrel{\circ}{X}_{53}=\stackrel{\circ}{Y}_{c}$

Vertical displacement of Carbody c $X_{55}=Z_{c} \Rightarrow \stackrel{\circ}{X}_{55}=\stackrel{\circ}{Z}_{c}=X_{56} \Rightarrow \stackrel{\circ}{X}_{56}=\stackrel{\circ}{X}_{55}=\stackrel{\circ}{Z}_{c}$

Yaw displacement of Carbody c $X_{57}=\psi_{c} \Rightarrow \stackrel{\circ}{X}_{57}=\stackrel{\circ}{\psi}_{c}=X_{58} \Rightarrow \stackrel{\circ}{X}_{58}=\stackrel{\circ}{X}_{57}=\stackrel{\circ}{\psi_{c}}$

Roll displacement of Carbody c $X_{59}=\phi_{c} \Rightarrow \stackrel{\circ}{X}_{59}=\stackrel{\circ}{\phi}_{c}=X_{60} \Rightarrow \stackrel{\circ}{X}_{60}=\stackrel{\circ}{X}_{59}=\stackrel{\circ}{\phi}_{c}$

Pitch displacement of Carbody c $X_{61}=\theta_{c} \Rightarrow \stackrel{\circ}{X}_{61}=\stackrel{\circ}{\theta}_{c}=X_{62} \Rightarrow \stackrel{\circ}{X}_{62}=\stackrel{\circ}{X}_{61}=\stackrel{\circ}{\theta}_{c}$ 